\title{
Pandinus imperator Scorpion Venom Blocks Voltage-Gated Potassium Channels in Nerve Fibers
}

\author{
Pamela A. Pappone ${ }^{1}$ and Michael D. Cahalan² \\ 'Department of Animal Physiology, University of California, Davis, California 95616, and '2Department of Physiology and \\ Biophysics, University of California, Irvine, California 92717
}

\begin{abstract}
We have examined the effects of venom from the scorpion Pandinus imperator on the membrane currents of voltageclamped frog myelinated nerve fibers using the Vaselinegap method. Crude venom, applied externally in concentrations from 50 to $500 \mu \mathrm{g} / \mathrm{ml}$, selectively blocked the voltagegated potassium currents without affecting nodal sodium currents or resting conductances. Block of potassium channels by Pandinus venom was highly dependent on the membrane voltage, being greater at negative potentials than at positive potentials. The blocking effects of Pandinus venom were irreversible on the time scale of our experiments; however, even high concentrations of venom failed to block potassium currents completely at positive potentials. These results suggest that Pandinus venom contains a component(s) that interacts specifically and strongly with a subpopulation of axonal potassium channels.
\end{abstract}

Many scorpion venoms contain toxins that modify action potential generation in nerves. Most of these venoms act selectively on the voltage-activated $\mathrm{Na}$ channels, inducing a prolonged nerve action potential through alterations in the gating properties of these channels (Cahalan, 1980; Catterall, 1984). A few scorpion venoms have been described that have, in addition to the $\mathrm{Na}$ channel toxins, minor components that act selectively on $\mathrm{K}$ channels (Koppenhoefer and Schmidt, 1968; Narahashi et al., 1972; Romey et al., 1975; Carbone et al., 1982, 1983; Miller et al., 1985). Like the $\mathrm{Na}$ channel scorpion neurotoxins, these $\mathrm{K}$ channel toxins are basic polypeptides with molecular weights of several thousand daltons. Unlike the $\mathrm{Na}$ channel toxins, which have voltage-dependent actions, the $\mathrm{K}$ channel toxins described thus far have actions that are independent of the membrane electrical potential. In addition, the effects of these $\mathrm{K}$ channel toxins are readily reversed upon their removal from the bathing medium.

In this paper we describe the effects of venom from the scorpion Pandinus imperator. Pandinus venom is not known to be deadly to vertebrates, and its effects in man are limited to pain at the site of envenomation (Keegan, 1980). We find that Pandinus venom acts specifically on axonal $\mathrm{K}$ currents in a voltagedependent manner, selectively blocking the delayed rectifier $\mathrm{K}$ channels of frog myelinated nerve fibers. Pandinus venom differs

\footnotetext{
Received Dec. 31, 1986; revised Apr. 13, 1987; accepted Apr. 23, 1987.

This work was supported by a National Institute of Health postdoctoral fellowship (to P.A.P.) and NIH Grants NS14609 (M.D.C.) and AM34766 (P.A.P.)

Correspondence should be addressed to Pamela A. Pappone at the above address.
}

Copyright (c) 1987 Society for Neuroscience $0270-6474 / 87 / 103300-06 \$ 02.00 / 0$ from other known $\mathrm{K}$ channel scorpion toxins in that the effects of the venom are highly voltage-dependent and are not readily reversible. The high affinity and specificity of the toxin could make Pandinus venom a useful tool for biochemical studies of voltage-gated $\mathrm{K}$ channels. A preliminary report of this work has been presented in abstract form (Cahalan and Culp, 1981).

\section{Materials and Methods}

Experiments were performed on single myelinated nerve fibers or skeletal muscle fibers of the bullfrog, Rana catesbeiana. Fibers were voltageclamped using the Vaseline-gap method (Dodge and Frankenhaeuser, 1958; Hille and Campbell, 1976), and records of membrane current were sampled and stored on the disk of a minicomputer as described previously (Cahalan and Pappone, 1981, 1983; Armstrong and Matteson, 1986). The amplitude of nodal membrane currents was calculated assuming a node resistance of $12.9 \mathrm{M} \Omega$ (Cahalan and Hall, 1982). In most experiments a $\mathrm{P} / 4$ pulse procedure was used to subtract the linear components from the membrane current records (Armstrong and Bezanilla, 1974). Fiber ends were cut in internal solutions of $120 \mathrm{mM} \mathrm{KF}$, 2 mM HEPES, pH 7.4, or 80 mM K 2 EGTA, 2 mM HEPES, pH 7.4. Extcrnal solutions were either normal Na-Ringer's, consisting of 115 $\mathrm{mm} \mathrm{NaCl}, 2.5 \mathrm{~mm} \mathrm{KCl}, 1.8 \mathrm{~mm} \mathrm{CaCl}, 5 \mathrm{~mm}$ 3-( $N$-morpholino)propanesulfonic acid (MOPS), pH 7.4, or K-Ringer's plus TTX, which had the same composition, except that the $\mathrm{NaCl}$ was replaced with $\mathrm{KCl}$ and $100 \mathrm{nM}$ TTX was added to block currents through the Na channels. The mounted fibers were allowed to equilibrate for $30 \mathrm{~min}$ before starting the experiment. The holding potential was nominally -100 or -110 $\mathrm{mV}$. Lyophilized Pandinus imperator venom was obtained from B. R. Tomberlin II (Duarte, CA) or from Latoxan (Rosans, France).

\section{Results}

Pandinus venom blocks $K$ channels in myelinated nerve fibers

Venom from the scorpion Pandinus imperator selectively reduces the voltage-dependent $\mathrm{K}$ currents of frog axons without affecting the $\mathrm{Na}$ currents. Figure $1 A$ illustrates the effects of 200 $\mu \mathrm{g} / \mathrm{ml}$ Pandinus venom on the $\mathrm{Na}$ and $\mathrm{K}$ currents measured in a voltage-clamped frog myelinated nerve fiber. In the control records, depolarization of the fiber elicits the familiar transient $\mathrm{Na}$ current, followed by a delayed and sustained outward $\mathrm{K}$ current. In the presence of Pandinus venom, the size of the delayed $\mathrm{K}$ current is substantially decreased, with no change in the amplitude or activation and inactivation kinetics of the $\mathrm{Na}$ currents. Peak $\mathrm{Na}$ and $\mathrm{K}$ currents from this experiment are plotted in Figure $1 B$, illustrating that approximately $50 \%$ of the $K$ current was blocked, while neither the magnitude nor the voltage dependence of the $\mathrm{Na}$ current activation was affected. The block of $\mathrm{K}$ currents by the venom was specific for axonal $K$ currents, since in 2 experiments crude venom in concentrations up to $500 \mu \mathrm{g} / \mathrm{ml}$ had no effect on the K currents of voltageclamped frog skeletal muscle fibers. 

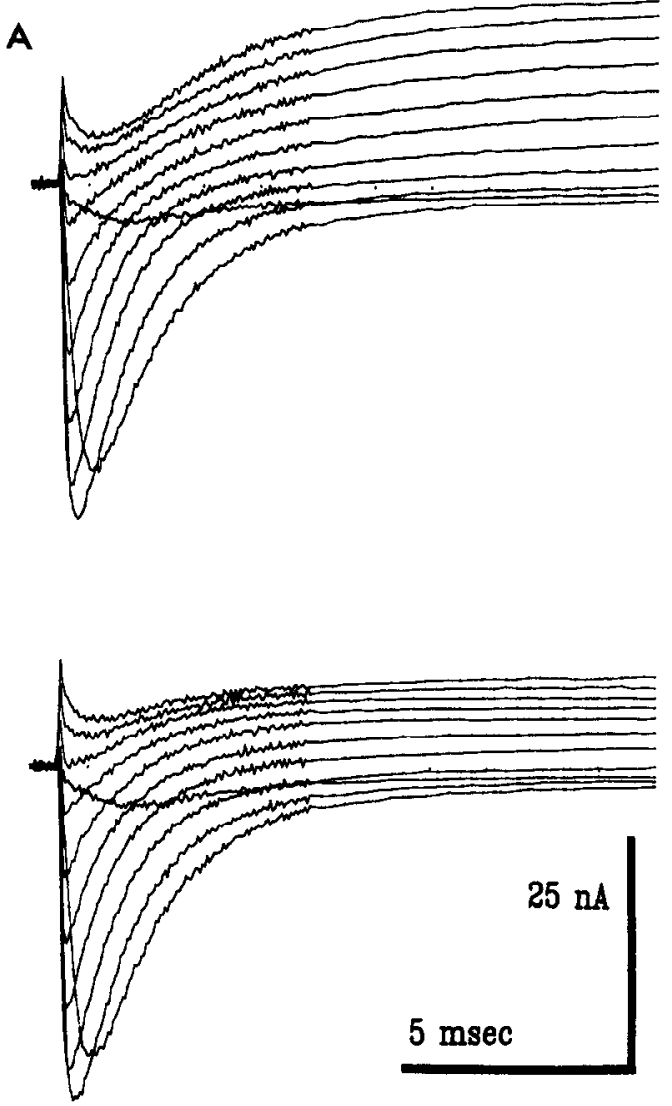

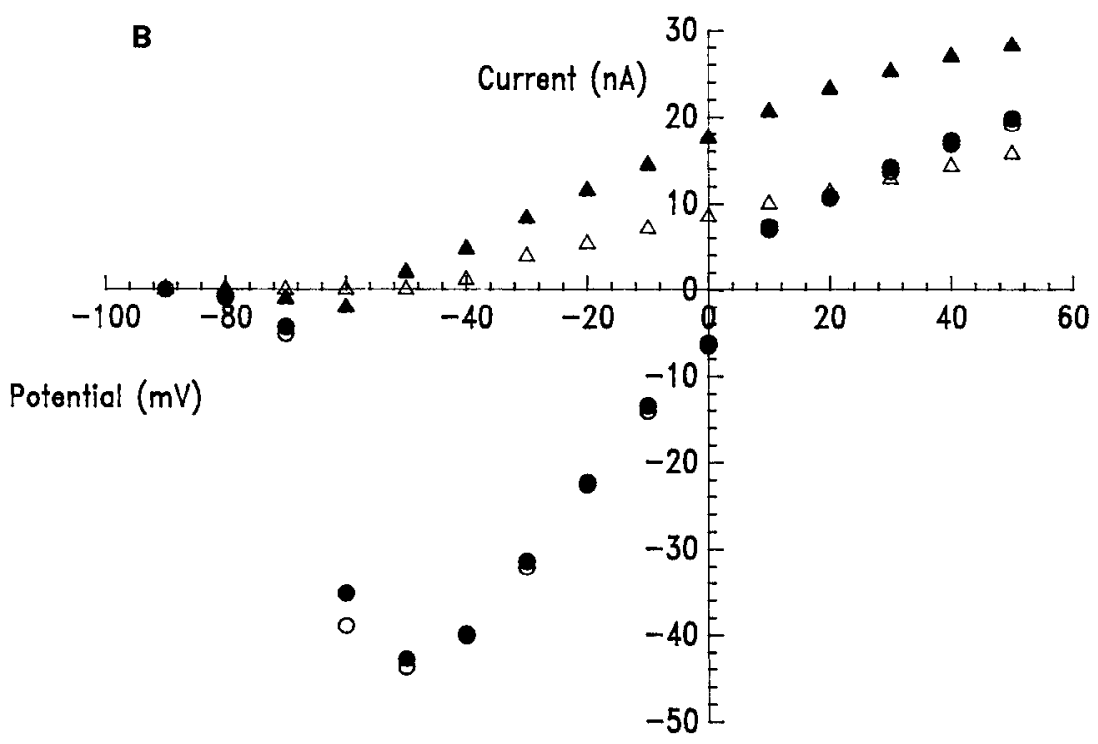

Figure 1. Pandinus imperator venom selectively blocks the voltage-dependent $\mathrm{K}$ conductance of nerve fibers. $A$, Membrane currents recorded in a voltage-clamped frog myelinated nerve fiber before (top) and $3 \mathrm{~min}$ after (bottom) exposure to $200 \mu \mathrm{g} / \mathrm{ml}$ Pandinus imperator venom. The membrane potential was held at $-100 \mathrm{mV}$ and stepped for $30 \mathrm{msec}$ to potentials ranging from -90 to $+50 \mathrm{mV}$ in increments of $10 \mathrm{mV}$ to produce each set of current records. External solution, Na-Ringer's. Internal solution, KF. Temperature, $10^{\circ} \mathrm{C}$. Current records filtered at $15 \mathrm{kHz}$. Fiber SVND18. B, Pcak Na (circles) and $\mathrm{K}$ (triangles) currents as a function of membrane potential from the records in $A$. Filled symbols are control values and open symbols represent measurements with venom present.

\section{Block of $K$ currents by Pandinus venom is voltage-dependent}

Pandinus venom blocks $\mathrm{K}$ currents more effectively at negative potentials than at positive membrane potentials. The voltage dependence of $\mathrm{K}$ channel block can be seen most clearly in the absence of other ionic currents. Figure 2 shows $\mathrm{K}$ currents measured in a nerve fiber bathed in a high-K solution. TTX is present to block the $\mathrm{Na}$ currents and linear components of the membrane current have been digitally subtracted from the record. Since the reversal potential for $\mathrm{K}$ channels is near $0 \mathrm{mV}$ under these ionic conditions, activation of the channels results in both inward and outward $\mathrm{K}$ currents in the control records. In the presence of Pandinus venom, the inward currents during the depolarizing voltage-clamp steps to negative potentials are abolishcd, whilc outward currents at more positive potentials are still present, although their amplitude is reduced. In Figure 2, all of the inward $\mathrm{K}$ current was blocked for a depolarization to $-50 \mathrm{mV}$, while the current during a depolarization to $+30 \mathrm{mV}$ was only $12 \%$ less than that of the control. Data for Figure 2 indicate that the block of $\mathrm{K}$ currents is dependent on voltage, but not on the direction of current flow, since inward tail currents are still present at the holding potential of $-110 \mathrm{mV}$ at the termination of the pulse in the presence of venom. Thus, the potential dependence of the venom block is evident whether the peak current during a depolarizing pulse or the magnitude of the tail current on returning to the holding potential is used to measure the amount of $\mathrm{K}$ conductance present.

The potential dependence of Pandinus venom's effects on $\mathrm{K}$ channel activation over the entire voltage range studied is shown in Figure 3, in which the relative $\mathrm{K}$ conductance derived from tail-current peak amplitudes measured at the holding potential is plotted as a function of activating pulse potential at 2 venom concentrations. The venom is seen to be more effective in blocking $\mathrm{K}$ currents elicited by small depolarizations than in blocking those caused by large depolarizations. $K$ currents were never completely blocked at positive membrane potentials by $\mathrm{Pan}$ dinus venom in our experiments, even at concentrations of 500 $\mu \mathrm{g} / \mathrm{ml}, 10$ times the concentration needed to block half the current at $-50 \mathrm{mV}$. The degree of block measured at negative and positive membrane potentials in various concentrations of Pandinus venom is shown in Table 1. These data show that the block of $\mathrm{K}$ current was more complete at $-50 \mathrm{mV}$ than at +30 $\mathrm{mV}$ for all concentrations of venom examined.

The voltage-dependence of Pandinus venom effects seem to be due to changes in the number of open $\mathrm{K}$ channels, since the conductance properties of the open channel apparently are unaffected by the venom. Figure 4 shows instantaneous currentvoltage relations measured in high-K solution with and without venom present. Under both conditions the relation is linear and reverses direction at the same potential, although the magnitude 
A

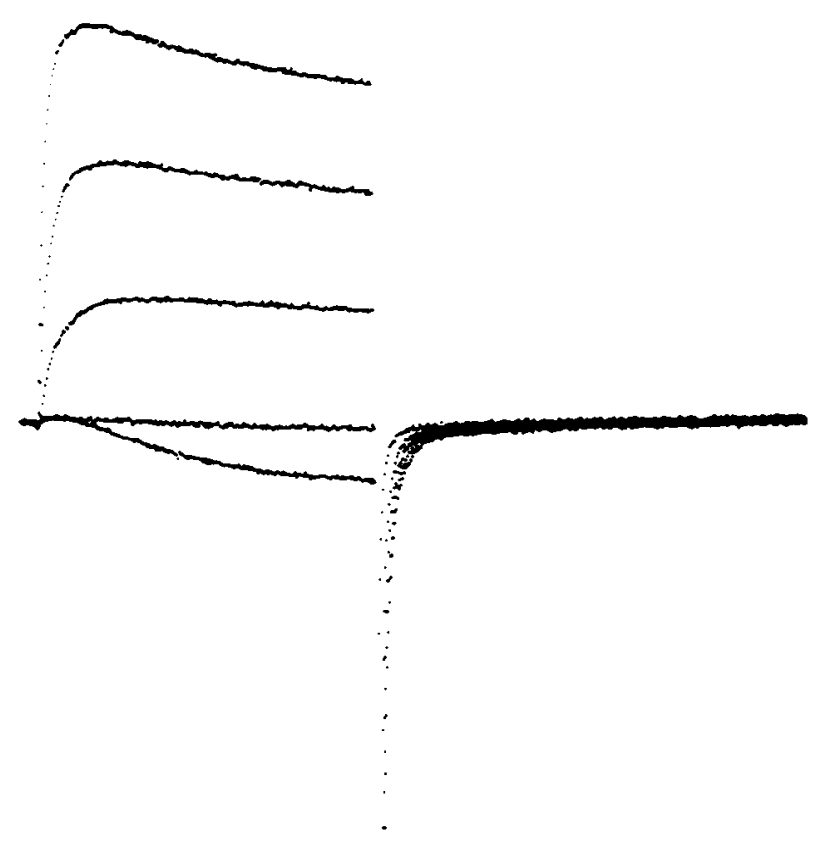

$\mathbf{B}$

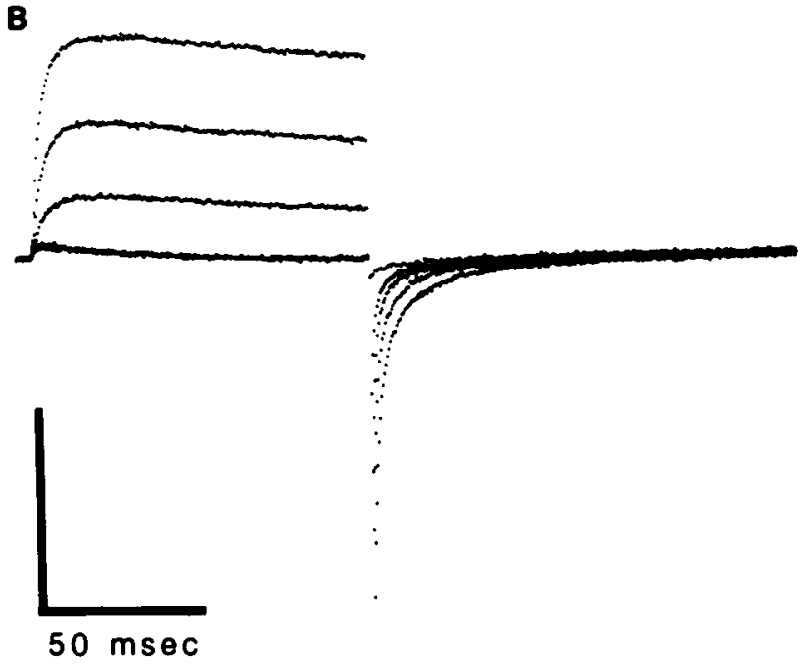

Figure 2. Membranc currents in a voltage-clamped nerve fiber. The fiber was bathed in K-Ringer's with $100 \mathrm{nM}$ TTX added to block the $\mathrm{Na}$ currents. The membrane potential was stepped to $-50,-30,-10$, 10 , and $30 \mathrm{mV}$ from the holding potential of $-110 \mathrm{mV}$. Internal solution, KF. $8^{\circ} \mathrm{C}$. Fiber SVND21. $A$, Control. $B$, Venom, $250 \mu \mathrm{g} / \mathrm{ml}$.

of the currents is reduced by the venom. Thus, if the venom affects the conductance properties of $\mathrm{K}$ channels, its effects are constant over the voltage range from -150 to $+30 \mathrm{mV}$.

\section{Pandinus venom alters channel-closing without affecting} channel-opening rates

While the voltage dependence of the steady-state activation of $\mathrm{K}$ channels is altered by Pandinus venom, this effect occurs without any changes in the rates of $\mathrm{K}$ channel opening. Figure 5 shows $\mathrm{K}$ currents activated by a depolarization to $+30 \mathrm{mV}$, measured with and without $250 \mu \mathrm{g} / \mathrm{ml}$ venom present, and scaled to have the same peak amplitude. The rate of $\mathrm{K}$ current activation is identical under the 2 conditions. Similar comparisons of the rates of turn-on of $\mathrm{K}$ currents over the whole voltage

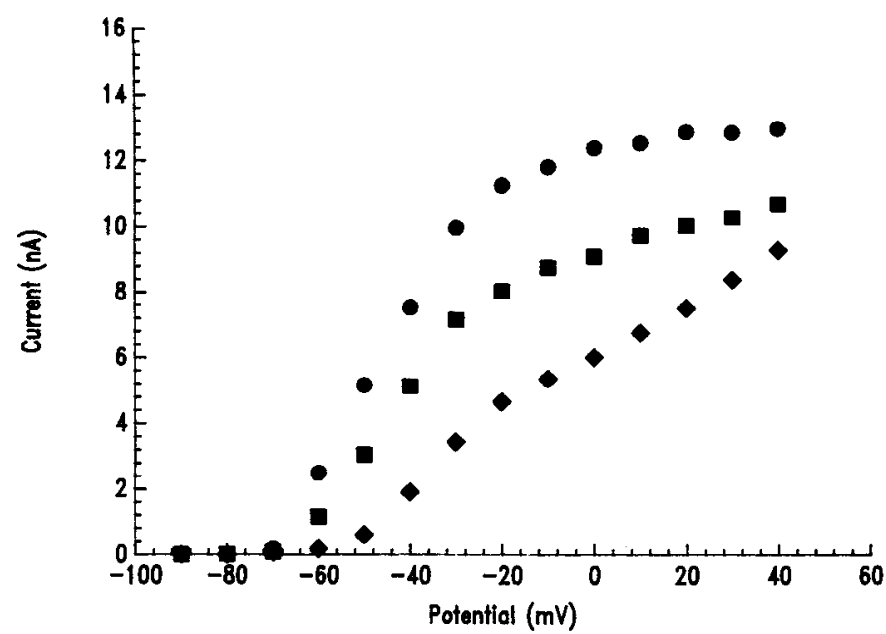

Figure 3. Effects of Pandinus venom on the activation of $\mathrm{K}$ currents. Peak inward tail current measured at the holding potential of $-110 \mathrm{mV}$ following a $100 \mathrm{msec}$ depolarization to the potential shown on the abscissa. Circles are control values, squares are measurements in $50 \mu \mathrm{g} /$ $\mathrm{ml} \mathrm{venom,} \mathrm{and} \mathrm{diamonds} \mathrm{in} 250 \mu \mathrm{g} / \mathrm{ml}$ venom. External solution, K-Ringer's. Same fiber and conditions as in Figure 2.

range in which $\mathrm{K}$ currents are activated failed to show any effect of Pandinus venom on channel-opening kinetics. In 5 experiments, the ratio of the time required for the $\mathrm{K}$ currents to reach their half-maximal value upon depolarization before and during exposure to $50-500 \mu \mathrm{g} / \mathrm{ml}$ venom was $0.98 \pm 0.06$, measured at $-50 \mathrm{mV}$.

In contrast to the unaffected channel-opening rates, $\mathrm{K}$ channel-closing rates were usually somewhat reduced at the holding potential following venom exposure, as can be seen in Figure 5. Comparison of the times required for half the channels to close upon repolarization to the holding potential of $-110 \mathrm{mV}$ showed that, for $50 \%$ deactivation of the current, the rates both increased and decreased in different fibers following exposure to the venom. Examination of deactivation rates over the voltage range between -160 and $-80 \mathrm{mV}$ showed a decrease in the voltage dependence of channel-closing rates. This resulted in closing kinetics that were faster than control values at more positive potentials, and slower than control values at more negative potentials, with the rates near the holding potential being little affected.

\section{Effects of Pandinus venom are not readily reversed}

Figure 6 shows K current magnitude measured before, during, and after exposure to the venom. At time 0 the nerve was exposed to $120 \mu \mathrm{g} / \mathrm{ml}$ of crude venom. The $\mathrm{K}$ current decreased rapidly, and within $100 \mathrm{sec}$ reached a new steady level. When the venom was washed off after a $125 \mathrm{sec}$ exposure, there was no recovery of the current in the remaining $10 \mathrm{~min}$ of the experiment. These effects were consistent throughout the course of our experiments. The onset of venom block was rapid, with a steady-state level of block being achieved within a few seconds. Block of $\mathrm{K}$ currents was irreversible, and in no experiment did we observe a recovery of current magnitude, even with wash times as long as $30 \mathrm{~min}$.

\section{Effect of Pandinus venom on nodal action potentials}

Block of voltage-dependent $K$ currents by Pandinus venom might be expected to prolong the duration of the axonal action poten- 


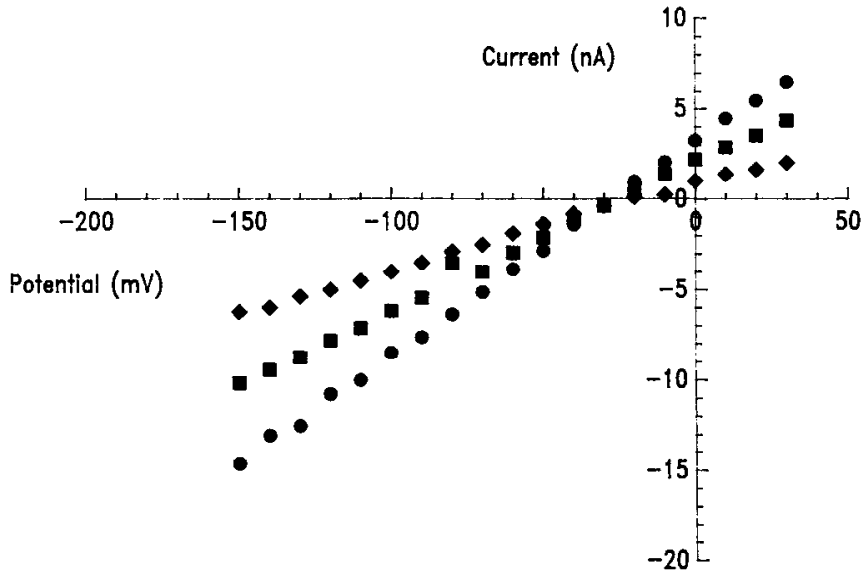

Figure 4. Instantaneous current-voltage relation in a nerve fiber. The fiber was bathed in K-Ringer's plus TTX before exposure to venom (circles) and in the presence of $50 \mu \mathrm{g} / \mathrm{ml}$ (squares) or $250 \mu \mathrm{g} / \mathrm{ml}$ (diamonds) venom. Peak tail-current amplitude was measured at the potential shown on the abscissa following a $40 \mathrm{msec}$ depolarization to $-30 \mathrm{mV}$, near the reversal potential for the $\mathrm{K}$ currents under our ionic conditions. Same fiber as in Figure 3.

tial by decreasing the rate of repolarization of the action potential. Thus, the net effect on nerve excitability would be similar to that of the scorpion toxins, which act by increasing Na current duration. However, as is shown in Figure 7, action potentials recorded in nerve fibers in the presence of Pandinus venom show only minimal differences from controls, these differences being a slight slowing of repolarization and a decrease in membrane conductance following the action potential. This finding agrees with the results obtained when decreasing the magnitude of the $\mathrm{K}$ current in calculated model action potentials, simulated using parameters derived for myelinated nerve fibers from voltage-clamp data (Hille, 1971). Evidently voltage-dependent K currents are not very important in determining the shape of the action potential in myelinated nerve, since in the model calculations, eliminating the voltage-gated $\mathrm{K}$ currents only increased the action potential duration by $25 \%$.

Comparison of zinc and Pandinus venom

Crude Pandinus venom contains approximately $2 \times 10^{-7} \mathrm{~mol}$ of zinc/mg of venom (W. Craig, personal communication). Since external $\mathrm{Zn}$ is known to affect the properties of $\mathrm{K}$ channels (Århem, 1980; Gilly and Armstrong, 1982), we explored the possibility that the effects of Pandinus venom were due to the $\mathrm{Zn}$ it contains. In agreement with previous studies, we found

Table 1. Voltage dependence of venom block of $K$ currents

\begin{tabular}{llll}
\multirow{2}{*}{$\begin{array}{l}\text { Venom conc. } \\
(\mu \mathrm{g} / \mathrm{ml})\end{array}$} & \multicolumn{2}{l}{ Block (\%) } & \\
\cline { 2 - 3 } 50 & $-50 \mathrm{mV}$ & $+30 \mathrm{mV}$ & $n$ \\
\hline 50 & $49 \pm 8$ & $16 \pm 9$ & 3 \\
250 & $77 \pm 6$ & $54 \pm 7$ & 5 \\
500 & 98 & 49 & 2 \\
& 98 & 65 & 2
\end{tabular}

Percentage block of $\mathrm{K}$ currents was measured from the ratios of the peak tail currents, in the presence of the indicated concentration of venom, to the current measure before venom application, at the holding potential of $-110 \mathrm{mV}$. Currents were elicited by a pulse to a membrane potential of -50 or $+30 \mathrm{mV}$, respectively. All measurements were made in high-K Ringer's.

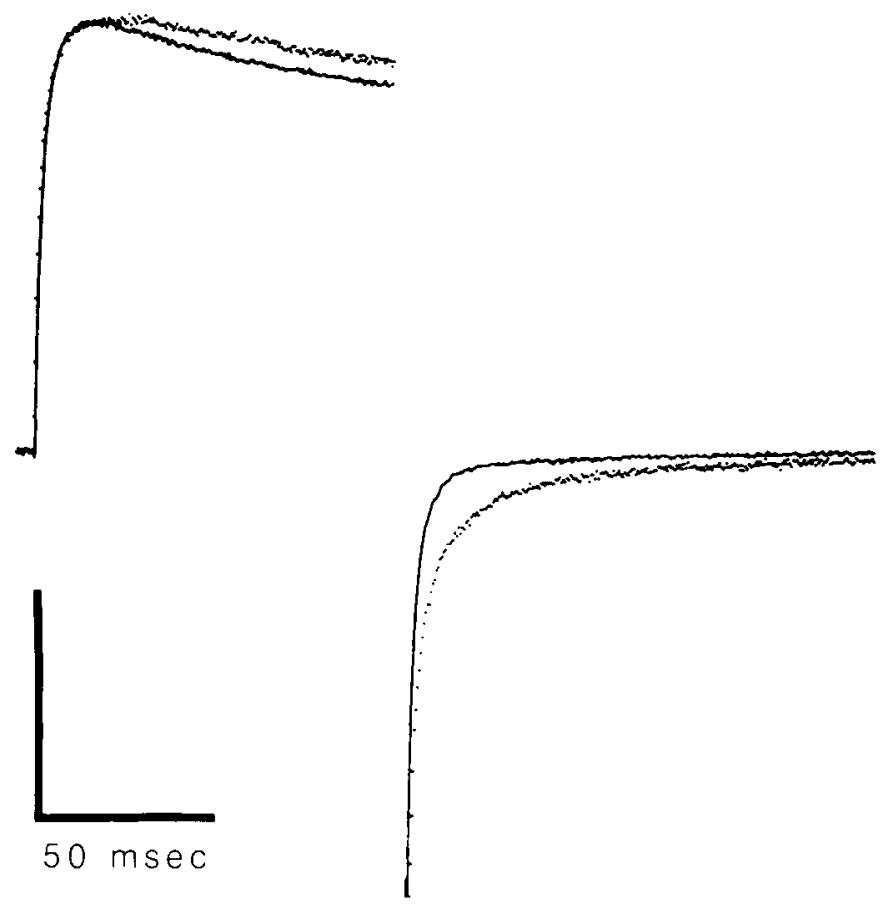

Figure 5. Comparison of $\mathrm{K}$ currents with and without venom. Membrane currents were measured during a $100 \mathrm{msec}$ pulse to $+30 \mathrm{mV}$ from the holding potential of $-100 \mathrm{mV}$. Solid line is the control record; dots represent the current recorded in the presence of $250 \mu \mathrm{g} / \mathrm{ml}$ venom, scaled by 1.8 to have the same amplitude.

that externally applied $\mathrm{Zn}(0.1-0.5 \mathrm{~mm})$ slows the opening of $\mathrm{K}$ channels and has little effect on the rate of channel closing. The steady-state activation of $\mathrm{K}$ current was shifted slightly (0-10 $\mathrm{mV}$ ) towards more positive potentials by $\mathrm{Zn}$ in this concentration range. However, the magnitude of the $K$ current was unaffected by $\mathrm{Zn}$. These effects of $\mathrm{Zn}$ were largely reversed within a few minutes of washing out the $\mathrm{Zn}$ solution. Thus, the effects of $\mathrm{Zn}$ are quite different from those of Pandinus venom, in that the kinetics of the currents are affected more than their magnitude by $\mathrm{Zn}$, and the $\mathrm{Zn}$ effects are readily reversed. We therefore conclude that free $\mathrm{Zn}$ itself is not responsible for the venom effects we have observed, although it remains possible that $\mathrm{Zn}$ participates in the action of other venom components.

\section{Discussion}

This paper describes the effects of Pandinus imperator scorpion venom on the ionic currents of voltage-clamped myelinated nerve fibers. We find that Pandinus venom blocks the currents through the voltage-gated potassium channels of nerve fibers specifically and irreversibly.

Previous voltage-clamp studies of scorpion venoms have shown that the venoms from Ieiurus quinquestriatus, Buthus tamulus, Tityus serrulatus, Androctonus australis Hector, and a number of species of Centruroides can all act to decrease the voltage-gated K currents of axons (Koppenhoefer and Schmidt, 1968; Narahashi et al., 1972; Romey et al., 1975; Carbone et al., 1982, 1983). The $\mathrm{K}$ channel toxins contained in these venoms share the properties of having effects that are independent of voltage, binding that is of relatively low affinity (in the $\mu \mathrm{M}$ range), and ready reversibility. In contrast, the action of $\mathrm{K}$ channel toxin(s) from the venom of Pandinus imperator is highly voltage-dependent, occurs apparently with high affinity, and is irreversible on the time scale of voltage-clamp experiments. 


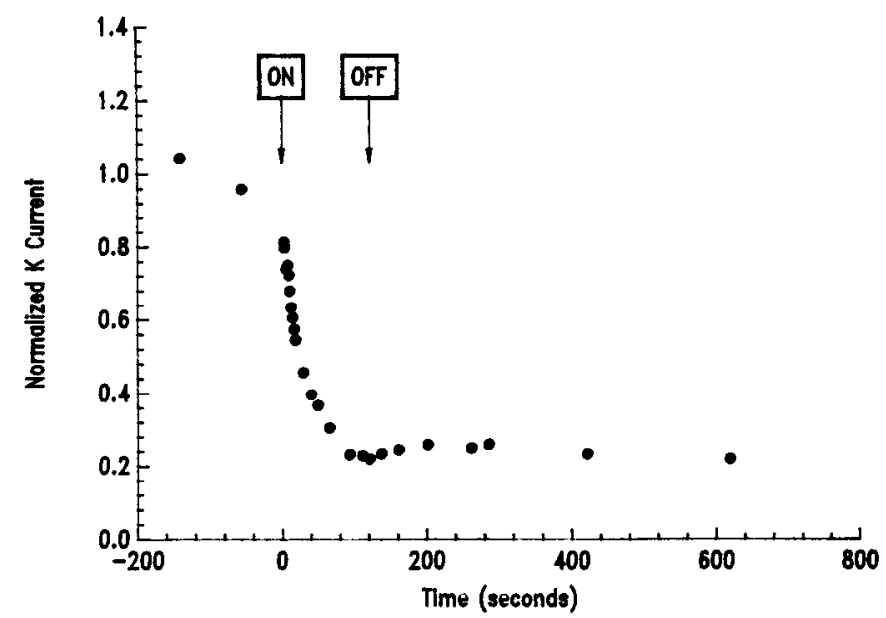

Figure 6. Time course of Pandinus venom effects. The ordinate shows the peak amplitude of the $\mathrm{K}$ current recorded during a $100 \mathrm{msec}$ pulse to $+10 \mathrm{mV}$, normalized to the average of the control values. At time $0,120 \mu \mathrm{g} / \mathrm{ml}$ of venom was washed onto the fiber $(O N)$. The venom was washed off after $125 \mathrm{sec}(O F F)$. External solution, K-Ringer's plus TTX. Internal solution, KF. $22^{\circ} \mathrm{C}$. Fiber SVND40.

Block of $\mathrm{K}$ current by Pandinus venom is much greater at negative membrane potentials than at positive potentials. The lack of venom effects on the shape of the instantaneous currentvoltage relation for $\mathrm{K}$ channels argues against the voltage dependence's being due to rectification of the open-channel conductance properties induced by the venom. Nor are our results consistent with the idea that the voltage dependence of venom effects is due to potential-dependent binding and dissociation of the toxin to the nerve membrane, since channel-opening kinetics are unaffected by the venom, strong depolarizations fail to remove the block, and repeated depolarization after washout of the venom does not restore the normal $\mathrm{K}$ conductance. Two remaining possibilities are that (1) there is a selective block of a subpopulation of $\mathrm{K}$ channels by the venom, or (2) there is an alteration of $K$ channel gating properties by venom binding.

The nodal membrane is known to contain at least 3 populations of $\mathrm{K}$ channels, which can be distinguished on the basis of their kinetic properties and susceptibility to block by 4-aminopyridine (Dubois, 1981). The bulk of the $\mathrm{K}$ conductance is due to 2 of these populations, termed the "fast K conductances," $\mathrm{g}_{\mathrm{f} 1}$ and $\mathrm{g}_{\mathrm{f} 2}$. The $\mathrm{g}_{\mathrm{f} 1}$ conductance activates in the voltage range from -80 to $-40 \mathrm{mV}$ and compromises $30-65 \%$ of the fast $\mathrm{K}$ conductance, with $\mathrm{g}_{\mathrm{f} 2}$ making $\mathrm{up}$ the rest of the fast $\mathrm{K}$ conductance and activating in the potential range from -40 to +50 $\mathrm{mV}$. Thus, a selective block of $\mathrm{g}_{\mathrm{f} 1}$ by Pandinus venom, or a greater susceptibility of the $g_{f 1}$ channels compared to that of the $\mathrm{g}_{\mathrm{f}}$ channels would result in the observed voltage dependence of its actions. Such a selective block of $g_{f 1}$ channels by a component of black mamba snake venom has recently been reported (Benoit and Dubois, 1986).

Pandinus venom reduces the voltage dependence of channelclosing rates, causing a decrease in the rate of closing at hyperpolarized potentials and an increase in the rate of closing at depolarized potentials, with little change in the closing rates near the holding potential. Thus, the apparent voltage-dependent block of $\mathrm{K}$ channels could be due to venom-induced changes in channel kinetics. If venom-modified channels had a less stable or energetically favorable open state, this could result in both an increase in channel-closing rates and a shift in the voltage

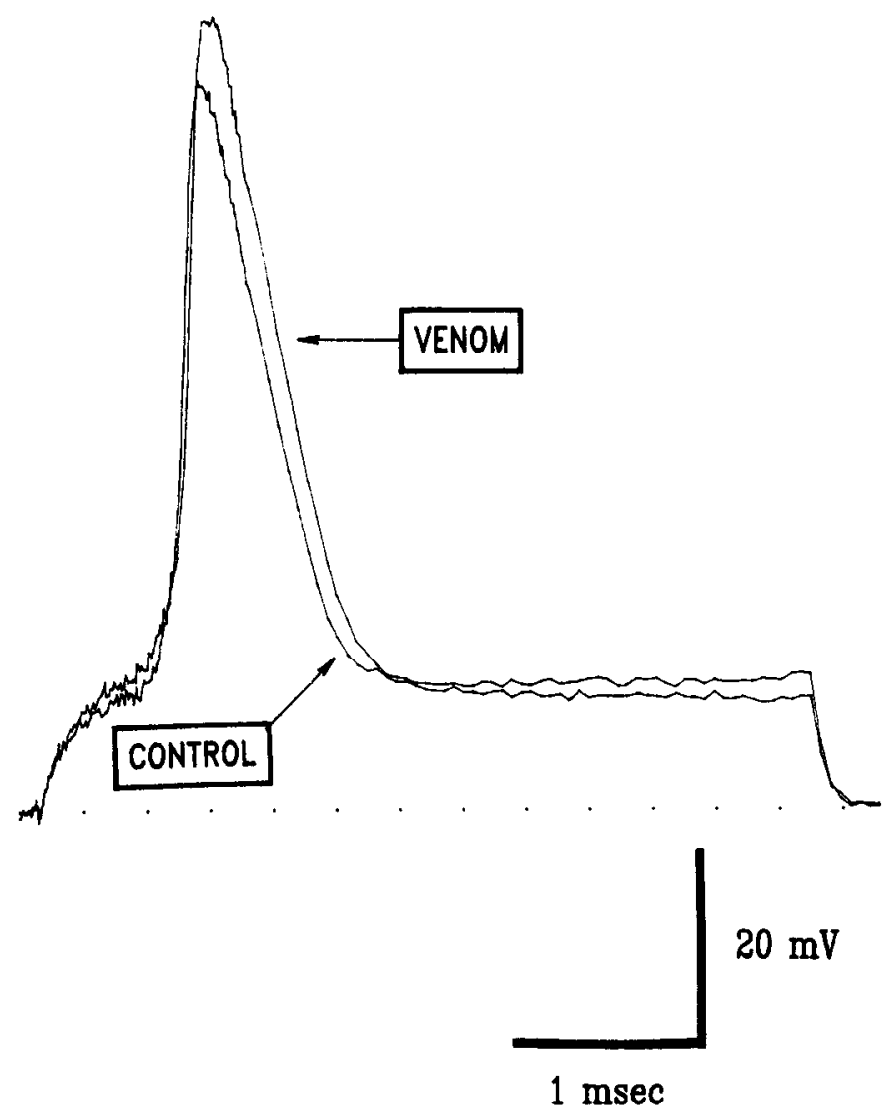

Figure 7. Superimposed action potentials in a myelinated nerve fiber, recorded before and during exposure to $100 \mu \mathrm{g} / \mathrm{ml}$ Pandinus venom, show only minimal differences. In each case an action potential was elicited from the fiber under "current-clamp" conditions by applying a $10 \mathrm{mV}$ stimulus to the cut end of the fiber. The resting membrane potential is assumed to be $-80 \mathrm{mV}$. Stimulus duration was $4 \mathrm{msec}$. External solution, Na-Ringer's. Internal solution, K-EGTA. $22^{\circ} \mathrm{C}$. Fiber SVND16.

dependence of steady-state activation to more depolarized potentials. Because $K$ channel activation is a multistep process, these changes in closing rates and steady-state activation could occur without corresponding alterations in the rates of channel opening. Such an action of Pandinus venom on $\mathrm{K}$ channel gating would resemble those seen with other scorpion venoms on $\mathrm{Na}$ channel gating, in which venom binding results in shifts in the potential dependence of channel activation or inactivation processes (Cahalan, 1980; Catterall, 1980). Alternatively, the changes in channel-closing rates seen in venom could be due to differences in the closing rates of blocked and unblocked subpopulations of $\mathrm{K}$ channels. The $\mathrm{g}_{\mathrm{f} 1}$ and $\mathrm{g}_{\mathrm{f} 2} \mathrm{~K}$ conductances have indistinguishable closing kinetics when measured at $-90 \mathrm{mV}$ (Dubois, 1981), but their deactivation kinetics may differ at other membrane potentials.

In contrast to the previously described $\mathrm{K}$ channel scorpion toxins, the toxic component(s) of Pandinus venom apparently bind to $K$ channels with a very high affinity. We have seen no reversal of Pandinus venom effects following washout of the venom for periods as long as $30 \mathrm{~min}$, suggesting that the binding of the toxic component(s) are at best only very slowly reversible. Preliminary experiments examining fractions of the crude venom also suggest a high-affinity binding by the toxin(s). More than $95 \%$ of the crude venom consists of inert mucous proteins 
(unpublished observations). Since $50 \mu \mathrm{g} / \mathrm{ml}$ of crude venom is sufficient to block $50 \%$ of the $\mathrm{K}$ current for a depolarization to $-50 \mathrm{mV}$, less than $1 \mu \mathrm{g} / \mathrm{ml}$ of active components must be capable of producing this level of block. If the toxin has a molecular weight of $5 \mathrm{kDa}$, similar to that of the other scorpion toxins, this would indicate a dissociation constant of less than $200 \mathrm{~nm}$ for a toxin that acted by simply blocking the channel. If the toxin acts by altering channel kinetics or by blocking a subset of the channels, as discussed above, the affinity would be even higher.

Animal toxins have proven invaluable in the purification and molecular characterization of other ion channels, such as the $\mathrm{Na}$ channel and the $\mathrm{ACh}$ receptor channel. Knowledge of the molecular properties of voltage-gated $\mathrm{K}$ channels has lagged behind these, at least in part because of the lack of suitable specific high-affinity ligands for these channels. The $\mathrm{K}$ channel toxins of Pandinus venom seem to have the characteristics necessary to be a valuable tool for isolation and characterization of axonal $\mathrm{K}$ channels.

\section{References}

Århem, P. (1980) Effects of some heavy metal ions on the ionic currents of myelinated fibers from Xenopus laevis. J. Physiol. (Lond.) 306: 219-231.

Armstrong, C. M., and F. Bezanilla (1974) Charge movement associated with the opening and closing of the activation gates of the $\mathrm{Na}$ channels. J. Gen. Physiol. 63: 533-552.

Armstrong, C. M., and D. R. Matteson (1986) The role of calcium ions in the closing of $\mathrm{K}$ channels. J. Gen. Physiol. 87: 817-832.

Benoit, E., and J.-M. Dubois (1986) Toxin I from the snake Dendroaspis polylepis polyepis: A highly specific blocker of one type of potassium channel in myelinated nerve fiber. Brain Res. 377: 374377.

Cahalan, M. D. (1980) Molecular properties of sodium channels in excitable membranes. In The Cell Surface and Neuronal Function. C. W. Cotman, G. Poste, and G. L. Nicholson, eds., pp. 1-47, Elsevier, NY.

Cahalan, M. D., and W. Culp (1981) Pandinus scorpion venom modifies $\mathrm{K}$ channel gating. Biophys. J. 33: $71 \mathrm{a}$.

Cahalan, M. D., and J. E. Hall (1982) Alamethicin channels incorporated into frog node of Ranvier: Calcium-induced inactivation and membrane surface charges. J. Gen. Physiol. 79: 411-436.
Cahalan, M. D., and P. A. Pappone (1981) Chemical modification of sodium channel surface charges in frog skeletal muscle by trinitrobenzene sulphonic acid. J. Physiol. (Lond.) 321: 127-139.

Cahalan, M. D., and P. A. Pappone (1983) Chemical modification of potassium channel gating in frog myelinated nerve by trinitrobenzene sulphonic acid. J. Physiol. (Lond.) 342: 119-143.

Carbone, E., E. Wanke, G. Prestipino, L. D. Possani, and A. Maelicke (1982) Selective blockage of voltage-dependent $\mathrm{K}^{+}$channels by a novel scorpion toxin. Nature 296: 90-91.

Carbone, E., G. Prestipino, E. Wanke, L. D. Possani, and A. Maelicke (1983) Selective action of scorpion neurotoxins on the ionic currents of the squid giant axon. Toxicon (Suppl. 3): 57-60.

Catterall, W. A. (1980) Neurotoxins that act on voltage-sensitive sodium channels in excitable membranes. Annu. Rev. Pharmacol. Toxicol. 20: 15-43.

Catterall, W. A. (1984) The molecular basis of neuronal excitability. Science 223: 653-661.

Dodge, F. A., and B. Frankenhaeuser (1958) Membrane currents in isolated frog nerve fiber under voltage-clamp conditions. J. Physiol. (Lond.) 143: 76-90.

Dubois, J. M. (1981) Evidence of the existence of three types of potassium channels in the frog Ranvier node membrane. J. Physiol. (Lond.) 318: 297-316.

Gilly, W. F., and C. M. Armstrong (1982) Divalent cations and the activation kinetics of potassium channels in squid giant axons. $J$. Gen. Physiol. 79: 965-996.

Hille, B. (1971) Voltage-clamp studies in myelinated nerve fibers. In Physiology and Biophysics of Excitable Membranes, W. J. Adelman, ed., pp. 230-246, Van Nostrand Reinhold, New York.

Hille, B., and D. T. Campbell (1976) An improved vaseline gap voltage-clamp for skeletal muscle fibers. J. Gen. Physiol. 67: 265-293.

Keegan, H. L. (1980) Scorpions of Medical Importance, U. P. Mississippi, Jackson, MS, p. 109.

Koppenhoefer, F., and H. Schmidt (1968) Effect of scorpion venom on ionic currents of the node of Ranvier. I. The permeabilities $P_{\mathrm{Na}}$ and $\mathrm{P}_{\mathrm{K}}$. Pfluegers Arch. 303: 133-149.

Miller, C., E. Moczydlowski, R. Latorre, and M. Phillips (1985) Charybdotoxin, a protein inhibitor of single $\mathrm{Ca}^{2+}$-activated $\mathrm{K}^{+}$channels from mammalian skeletal muscle. Nature 313: 316-318.

Narahashi, T., B. I. Shapiro, T. Deguchi, M. Scuka, and C. M. Wang (1972) Effects of scorpion venom on squid axon membranes. Am. J. Physiol. 222: 850-857.

Romey, G., R. Chicheportich, and M. Lazdunski (1975) Scorpion neurotoxin - a presynaptic toxin which affects both $\mathrm{Na}^{+}$and $\mathrm{K}^{+}$channels in axons. Biochem. Biophys. Res. Commun. 64: 115-121. 